Article

\title{
Ethnic Identity, Implicit Associations, and Academic Motivation of Hispanic Adolescents
}

\author{
Tim Urdan * and Daniel Teramoto
}

Citation: Urdan, T.; Teramoto, D. Ethnic Identity, Implicit Associations, and Academic Motivation of Hispanic Adolescents. Adolescents 2021, 1, 252-266. https://doi.org/ 10.3390/adolescents1030019

Academic Editor: Arsaell Arnarsson

Received: 30 May 2021

Accepted: 1 July 2021

Published: 6 July 2021

Publisher's Note: MDPI stays neutral with regard to jurisdictional claims in published maps and institutional affiliations.

Copyright: (c) 2021 by the authors. Licensee MDPI, Basel, Switzerland. This article is an open access article distributed under the terms and conditions of the Creative Commons Attribution (CC BY) license (https:/ / creativecommons.org/licenses/by/ $4.0 /)$.

\begin{abstract}
Department of Psychology, Santa Clara University, Santa Clara, CA 95053, USA; dteramoto@scu.edu * Correspondence: turdan@scu.edu
\end{abstract}

\begin{abstract}
One of the major tasks of adolescence is to integrate the different aspects of identity into a coherent sense of self. Prior research has found that under certain circumstances, students who identify as members of groups about which there are negative stereotypes can experience a disassociation between their academic identity (i.e., academic self-concept) and the aspect of their identity that is negatively stereotyped (i.e., their ethnic or gender identity). In this study, we examined the association between ethnic identity, academic self-concept, valuing of school, and feelings of belonging among a sample of Hispanic high school students attending a majority-Hispanic high school. In addition, we used an Implicit Associations Test (IAT) to assess their implicit associations between success and ethnic group (Hispanic or white). Results indicated that centrality of ethnic identity was positively correlated with academic self-concept and the regard dimension of ethnic identity was associated with feelings of belonging. The IAT indicated that Hispanic students had implicitly associated success more with being white than with being Hispanic.
\end{abstract}

Keywords: academic motivation; ethnic identity; implicit associations

\section{Introduction}

Ethnic identity is a multi-faceted construct. One popular conceptualization of ethnic identity, the Multidimensional Model of Racial Identity (MMRI) [1], divides ethnic identity into four dimensions: centrality, salience, regard, and ideology. Centrality refers to the importance or weight of one's ethnicity to their overall sense of self. How conscious one is of their ethnicity in any given situation is referred to as salience. The regard dimension refers both to one's feelings about the ethnic group with which they identify and their perceptions about how others view their ethnic group. Ideology is about one's beliefs regarding how members of one's ethnic group should think and behave.

For most students in the ethnic majority in the United States, ethnic identity is generally not a central feature of overall self-perceptions, and the salience of ethnic identity is usually quite low. For students in the minority in the U.S., however, ethnic identity is often central and salient. Some researchers have argued that for students who often experience racism in school and in the broader society, a strong ethnic identity can serve as a buffer against such racism and provide academic benefits [2]. For example, research has found that ethnic identity was positively associated with academic motivational beliefs, such as intrinsic valuing of academic achievement and feelings of belonging in school $[3,4]$. The argument is that strong feelings of connection with one's ethnic identity, and positive feelings about one's ethnic group, create resilience against negative stereotypes about one's ethnic group and personal experiences of racism.

However, other research has painted a more complex picture about the association between ethnic identity and academic motivation for some students, especially students who belong to ethnic or cultural groups that have negative stereotypes about their academic abilities [5,6]. In the U.S., such negative stereotypes exist about Hispanic students [7]. (In this paper, we use the pan-ethnic term Hispanic to refer to students of Latin-American descent. Of the various terms used to refer to this population (e.g., Latino/a, Latinx, 
Chicano/a, etc.), Hispanic or Latino were the preferred pan-ethnic terms of most members of the population [8].) In addition, the academic context may affect the association between ethnic identity and academic motivation for Hispanic students. For example, whether Hispanic students are in the ethnic majority or the minority may have an effect. In collegetrack high school classrooms and selective four-year universities, Hispanic students are often in the minority [6,9].

\subsection{The Intersection of Ethnic Identity and Stereotype Threat}

Stereotype threat is defined as a "state of psychological discomfort that is thought to arise when individuals are confronted with a negative stereotype about their own group in a situation in which the negative stereotype could be confirmed" [10], p. 2. When stereotype threat is activated, it can undermine performance by drawing cognitive resources away from the task and toward concern about confirming the negative stereotype. Over time, as stereotype threat impedes performance, students can experience a disidentification with the domain (e.g., a devaluing of math, or of school more broadly, as an important aspect of one's self-perception) [11,12]. As the definition indicates, certain conditions must be present for stereotype threat to exert its negative influence. First, there must be negative stereotypes about one's abilities. Second, one must be aware of these negative stereotypes. Third, one must identify with the group about which there are negative stereotypes. Finally, one must be in a situation in which the stereotype threat becomes activated. In other words, an opportunity must arise in which the negative stereotype can be affirmed, and there must be people there who can witness this stereotype affirmation. For example, a female college student who is aware of the negative stereotype about women's mathematical abilities will not be affected by stereotype threat while in English class and is less likely to be affected by it if she is in a math class but attends an all-female university. In contrast, if she is in a coeducational classroom and about to take a math test, stereotype threat is likely to be activated.

As identifying with the negatively stereotyped group is a prerequisite for stereotype threat activation, the combination of negative stereotypes about the academic abilities of one's ethnic group and a strong ethnic identity (i.e., centrality) may weaken academic motivation or performance in some situations. For example, there is evidence that for some immigrant students, higher stereotype vulnerability combined with stronger ethnic identity is associated with higher dropout rates, stronger decline in GPA, and lower levels of academic belonging compared to non-immigrants or other students who did not face the stereotype vulnerability [13]. Similarly, a study of Hispanic college students found that when negative academic stereotypes about Hispanics were made salient, students with stronger ethnic identification performed worse on a math exam than those with weaker ethnic identification [14]. Consistent with these results, researchers have speculated that Hispanics with stronger ethnic identification are more susceptible to stereotype threat effects because their membership in the stereotyped ethnic group is a more salient feature of their self-concept [6].

Other research has found that for some minoritized students, the association between ethnic identity and academic self-concept was weak. In their study of 9 th grade students, Fuligni and his colleagues found that ethnic identity was positively associated with several motivational beliefs (e.g., intrinsic value of school, academic value, utility of education), but was not correlated with academic self-concept [3]. These results were found with a multi-ethnic sample that included Hispanic students, but the researchers did not examine Hispanic students separately in this analysis. With a sample of Hispanic students attending a majority-white, four-year university, Urdan also found that ethnic identity was not significantly associated with academic self-concept [15]. This research suggests that there may be a disassociation between academic and ethnic identities among some Hispanic students, especially when they are in the minority in an academic context and stereotype threat may be activated. 


\subsection{The School Context}

The associations among stereotype threat, ethnic identity, and academic motivation and performance may depend on the ethnic makeup of the learning environment. Stereotype threat is most likely to be activated when ethnic identity is salient. Awareness of ethnic identity tends to increase in contexts where one is in the ethnic minority. Much of the research examining the associations between ethnic identity and stereotype threat have occurred in majority-white universities, where Hispanic or African American students are in the minority. In such contexts, in addition to the negative effects on academic performance described above, strong ethnic identity combined with stereotype threat may affect feelings of belonging among Hispanic students who are in the minority. Erba [16] found that undergraduate Hispanic students at a majority-white university were more likely to change their behavior in an effort to counter negative stereotypes if they had a strong ethnic identity. Conversely, Hispanic students at the same university who had a weaker ethnic identity did not believe that they needed to change their behavior around non-Hispanic students. These students talked about how their white peers would see them as equal because they were all attending the same university. The lack of perceived need to alter their behavior suggests stronger feelings of belonging at the university among Hispanic students with weaker centrality of ethnic identity.

There has also been a limited amount of research examining the effects of stereotype threat in pre-college populations. In one study conducted at a majority-white middle school, Hispanic students who completed affirmation writing exercises, where they were encouraged to write about their key values and different times in which they were important, over the course of the school year earned higher grades and were less likely to have their sense of academic belonging and motivation be negatively impacted by identity threat when compared to Hispanic students who did not complete the writing exercises [17]. The effects of the intervention persisted two years later with the grade point averages of the affirmed students being higher than those of the non-affirmed students. This suggests that there can be interventions that can be put in place to counteract the stereotype threats that Hispanic students face when the salience of ethnic identity is heightened. In the present study, we were interested in examining the intersection of ethnic identity, stereotypes, and academic motivation among Hispanic students attending a majority-Hispanic high school.

\subsection{Sub-Conscious Processes}

Non-conscious processes have long been recognized as a source of motivation and behavior $[18,19]$. In recent years there has been increasing attention focused on nonconscious processes, both in the scientific literature [20] and the popular literature [21]. Measuring implicit associations is one increasingly popular method of examining nonconscious processes. Implicit associations refer to connections that people make between certain stimuli or concepts even when they are not aware that they are making such an association, or that the implicit association is affecting behavior. Scores of studies have examined implicit associations to assess everything from voting tendencies [22] to stereotype threat [23] to a variety of different "isms" such as racism [24] and agism [25]. This research has documented that self-report data are often at odds with implicit associations. For example, people who profess to harbor no ill will toward members of ethnicities different from their own nonetheless have patterns of implicit associations that reveal less favorable perceptions of other ethnic groups than they hold of their own ethnic group [24].

The extant research examining the associations between ethnic identity and academic motivation have relied almost exclusively on explicit (i.e., self-report) measures. As noted earlier, some of this research has found a positive, buffering effect of a strong ethnic identity on measures of academic motivation and performance [3,26], but this association may be moderated by stereotype threat conditions that exist in a given achievement context [14]. But how might sub-conscious processes affect Hispanic students? Students who attend to societal messages may become aware of the negative stereotypes about the academic abilities of Hispanic students. Even if they do not believe these negative 
stereotypes explicitly, it is possible that they may internalize these messages and form implicit associations linking success more with being white than with being Hispanic. Such sub-conscious processes may undermine the academic motivation of Hispanic students. We were interested in examining the implicit associations of Hispanic high school students attending a majority-Hispanic school.

\subsection{The Present Study}

Explicit measures (i.e., survey data) have revealed that Hispanic students, a group with negative stereotypes about their academic abilities, may experience limited academic motivation benefits of a strong ethnic identity, especially when they are in the minority in the classroom or school. In the present study, we wanted to examine whether this disassociation that has been found between ethnic identity and academic self-concept among Hispanic college students would also be found among a sample of Hispanic high school students attending a majority-Hispanic school. We hypothesized that when Hispanic students are in the majority ethnic group in their school and classrooms, stereotype threat would be less active, ethnic identity would be less salient, and a positive association between ethnic identity and academic self-concept would be found. However, given the prevalence of negative stereotypes about the academic abilities of Hispanic students in the broader U.S. society, we also hypothesized that the implicit associations of Hispanic high school students would follow a stereotypical pattern that associates success more with Caucasian than with Hispanic ethnicity.

\section{Methods}

Participants

A sample of 95 students from a medium-sized high school (approximately 1500 students in grades 9 through 12) in the San Francisco Bay Area participated in this study. The high school has a student population that is over $99 \%$ minority (i.e., non-white) and $85 \%$ Hispanic. The student population is relatively low achieving with $17 \%$ of the students identified as proficient in math and $43 \%$ proficient in reading, according to standardized tests administered by the state. In addition, most of the students (77\%) are considered economically disadvantaged.

Participants were provided with a list of dozens of cultural and ethnic labels and asked to select up to five labels that described themselves. Then, participants were asked to select the one label that they felt best described their cultural or ethnic background. Of the original sample, 84 participants selected a best-fit label that would fall under the broad category of Hispanic (i.e., Hispanic, Mexican, Mexican American, Hispanic/a, Chicano/a, Central American, etc.). As Hispanic adolescents were the focus of the present study, those students in the original sample who did not identify as Hispanic were excluded from the study.

Our remaining sample of 84 Hispanic students was evenly divided between male and female participants. There were an even number of 9 th and 10 th graders (49\% each) as well as one 11th and one 12th grade student. Roughly a quarter (27.4\%) of the sample was born outside of the U.S. and nearly $80 \%$ said their mother, father, or both parents were immigrants to the U.S. The majority of the sample (85\%) spoke Spanish as their first language, and only $26 \%$ believed that they had at least one parent who graduated from high school. Although most of the students in our sample learned to speak Spanish as their first language, all of them were labeled as proficient in English according to testing conducted by the school district. As per state law, all of the instruction in the school, except for in foreign language classes, was conducted in English. (A summary of the demographic characteristics of students who participated in this study is presented in Table 1). 
Table 1. Summary of participant demographic characteristics.

\begin{tabular}{ll}
\hline Demographic Variable & Percentage in Each Category \\
\hline Gender & $50 \%$ male, 50\% female \\
\hline Grade & $49 \%$ 9th, $49 \%$ 10th, 1\% 11th, 1\% 12th \\
\hline First language spoken & $85 \%$ Spanish as first language, 15\% English as first language \\
\hline Parent graduated high school & $\begin{array}{l}26 \% \text { at least one parent graduated high school, 74\% } \\
\text { neither parent graduated high school }\end{array}$ \\
\hline Student is immigrant & $27.4 \%$ immigrant, 72.6\% born in U.S. \\
\hline $\begin{array}{l}\text { One or both parents are } \\
\text { immigrants }\end{array}$ & $\begin{array}{l}80 \% \text { had at least one immigrant parent, } \\
20 \% \text { had parents born in U.S. }\end{array}$ \\
\hline
\end{tabular}

\section{Measures}

\subsection{Survey}

The survey was organized into four sections. First, participants were asked to provide demographic information including gender, year in school, birth country for each parent, frequency of English language use with parents and with friends, and the preferred ethnic or cultural label of the participant (e.g., Asian American, Hispanic, White, etc.). This method of determining participants' preferred ethnic identity label was developed by Alarcón and colleagues [27] and reported in Fuligni et al. [3]. Second, participants were asked about their ethnic identity, including how important their ethnic identity was to their self-concept (Centrality of Ethnic Identity, sample item: "In general, being a member of my ethnic group is an important part of my self-image.") and how positively they felt about their ethnic group (Regard for Ethnic Group, sample item: "I feel good about the people in my ethnic group"). To measure these aspects of ethnic identity, we used a subset of items that were used by Fuligni and his colleagues [3]. We used four of the seven items from Fuligni to measure Centrality of ethnic identity and three of eight items to measure the Regard dimension of ethnic identity. In the third section of the survey, participants were asked about academic motivation variables, including academic selfconcept, valuing of academics, and feelings of belonging at school. These measures were adapted from the Patterns of Adaptive Learning Survey (PALS; [28]). Whereas the PALS items referred to specific academic subjects and classrooms, the items in our study referred to school in general. This section also included an item to assess students' awareness of stereotypes about their cultural group: "People outside of my ethnic group expect members of my ethnic group to do well in school." Finally, students were asked about their plans to attend college and how family members and their cultural backgrounds influenced their college attendance plans, if at all. Most of the items (ethnic identity dimensions, academic motivation) employed a 5-point, Likert-like scale, with $1=$ "Not at all true for me" to $5=$ "Very true for me". Individual items were averaged to produce scales. All scales had Cronbach's alpha levels above 0.65. A final item asked participants to identify which culture they felt most strongly connected to: the native culture of the family, the mainstream culture in the U.S., neither, or both. This item is based on the ideas of Berry [29,30] and others about biculturalism and the various forms it can take. Sixty-one percent of participants reported identifying as bi-cultural (identifying with their family's native culture as well as American culture), 18\% favored the family's native culture, $7 \%$ identified more with American culture, and 11\% said neither culture. Surveys were written in English on one side and Spanish on the other. No participants completed the Spanish version of the survey.

\subsection{Implicit Associations Test (IAT)}

Participants completed a measure of their implicit associations among success and failure for Hispanic and Caucasian ethnic groups. The IAT was created using DirectRT software and administered via computer. In this test, participants were first presented 
with a series of words, one at a time, and participants indicated whether they believed the word represented success or failure by pressing the appropriate key on the keyboard. For example, in the first trial users were presented with a word in the middle of the screen (e.g., "Achievement") and had to press the letter D if they thought the word represented success or the letter $\mathrm{K}$ if they thought the word represented failure. "Success" appeared in the upper left corner of the screen in this trial and "Failure" appeared in the upper right corner of the screen. In the second trial, the response options were switched so that "Success" appeared in the upper right corner of the screen and "Failure" appeared in the upper left corner. Twenty words that could be associated with success or failure were presented in random order and participants were asked to respond to each word presented in the middle of the screen as quickly as they could but making as few errors as possible. The computer recorded reaction time (in milliseconds) and whether the participant correctly classified each word. Examples of success words included "Achievement", "Graduate", "Motivated", and "College". Examples of failure words included "Disappointment", "Unsuccessful", "Loser", and "Dropout".

In the second section of the IAT, participants were presented a set of 20 photographs of faces, in random order. Each face was either of a Caucasian adult person or a Hispanic adult person and were evenly divided into male and female faces for each ethnic group. The users then had to classify the faces as either Caucasian or Hispanic. As with the classification of words in the first two trials, the classification of photos occurred over two trials, counterbalancing the placement of "Caucasian" and "Hispanic" in the upper left and right corners of the screen and using the " $\mathrm{D}$ " and " $\mathrm{K}$ " keys to classify the faces. Again, reaction time and correctness of each response were recorded.

In the third section of the test, participants were presented with either a word or a picture. They had to indicate whether the word or picture represented Success/Caucasian (paired together) or Failure/Hispanic (paired together). For example, a word was presented in the middle of the screen (e.g., "Graduate") and if the participant thought this word was associated either with Success or Caucasian, they should have hit the " $\mathrm{D}$ " key, but if they thought the word represented Failure or Hispanic, they should have hit the " $\mathrm{K}$ " key. Twenty words or pictures were presented in random order over four trials, with two trials pairing Success/Hispanic-Failure/Caucasian and the other two pairing Failure/HispanicSuccess/Caucasian. The pairings and placements of the pairings were counter-balanced across the four trials. Two sample screenshots of this portion of the IAT, one with a picture as the prompt and another with a word as the prompt, are presented in the Appendix A. Reaction time and correctness of classification were recorded.

The goal of the IAT was to determine whether participants had stronger associations between success and culture for Caucasian or Hispanic ethnic groups. For example, if participants had a stronger association between success and Caucasians than they did for success and Hispanics, it should have taken them longer to react when "Success" was paired with "Hispanic" than when "Success" was paired with "Caucasian." Similarly, participants should have responded more quickly when "Failure" was paired with "Hispanic" than when it was paired with "Caucasian" if they had an association, conscious or not, between failure and Hispanic ethnic groups.

\subsection{Procedure}

Participants came to a large meeting room on their high school campus in groups of four. Research assistants greeted them and explained that the general purpose of the study was to examine how participants thought about themselves as students and as members of their respective ethnic groups. Then, participants read and signed informed consent forms. While two students completed the IAT on separate laptop computers, the other two completed the surveys. When finished with the first measure, the two groups of students switched places to complete the second measure. Students were separated and not allowed to talk or interact while completing either the survey or the IAT measures. 
Then, participants were given the lead author's name and email address and told to contact him with any questions or to learn the results of the study if they were interested.

\section{Results}

\subsection{Correlations Among Ethnic Identity and Motivation Variables}

Means, standard deviations, and bivariate correlation coefficients for the survey measures of ethnic identity, academic motivation, and stereotype awareness are presented in Table 2. The means reveal that the Centrality and Regard dimensions are quite high in this sample ( $M s>3.75$ on a 5-point scale). Similarly, the means for Belonging $(M=4.01)$ and Academic Value $(M=3.80)$ are also quite high. The means for Academic Self-Concept and Stereotype Awareness were more moderate $(M=3.29$ and $M=3.31$, respectively). Independent $t$ tests revealed no significant differences by gender or generational status (i.e., whether students were born in the U.S. or immigrated to the U.S.) on any of the ethnic identity or academic motivation survey measures.

Table 2. Means, standard deviations, and correlations for ethnic identity and academic motivation variables.

\begin{tabular}{|c|c|c|c|c|c|c|}
\hline & $\begin{array}{l}\text { Mean } \\
\text { (S.D.) }\end{array}$ & EI-C & EI-R & ASC & AV & SA \\
\hline EI: Centrality & $\begin{array}{c}3.80 \\
(1.08)\end{array}$ & - & & & & \\
\hline EI: Regard & $\begin{array}{c}3.87 \\
(0.81)\end{array}$ & $0.50^{* *}$ & - & & & \\
\hline Academic SC & $\begin{array}{c}3.29 \\
(0.89)\end{array}$ & $0.29 * *$ & 0.21 & - & & \\
\hline Academic value & $\begin{array}{c}3.82 \\
(0.94)\end{array}$ & 0.03 & 0.14 & $0.47^{* *}$ & - & \\
\hline Belonging & $\begin{array}{c}4.04 \\
(1.08)\end{array}$ & -0.04 & 0.28 * & 0.19 & $0.34^{* *}$ & \\
\hline Stereotype awareness & $\begin{array}{c}3.31 \\
(1.33)\end{array}$ & $0.23 *$ & 0.05 & -0.03 & 0.04 & -0.03 \\
\hline
\end{tabular}

* indicates $p<0.05,{ }^{* *}$ indicates $p<0.01$. EI-C $=$ Ethnic Identity, Centrality. EI-R = Ethnic Identity, Regard, $\mathrm{ASC}=$ Academic Self-Concept, $\mathrm{AV}=$ Academic Valuing, $\mathrm{SA}=$ Stereotype Awareness.

We were most interested in the correlations between the Centrality dimension of ethnic identity and the three motivation measures, particularly self-concept. There was a moderate, positive, and statistically significant correlation between the centrality dimension of ethnic identity and academic self-concept $(r=0.29, p<0.01)$. Students who were more likely to say that their ethnic identity was an important part of their overall identity were more likely to report positive perceptions of their academic abilities. This dimension of ethnic identity was not significantly correlated with the valuing of academics or feelings of belonging in school but was positively correlated with the perception that people outside of one's ethnic group expect those within the ethnic group to do well in school. The Regard dimension of ethnic identity was positively correlated with feelings of belonging in school $(r=0.28, p<0.01)$, but was unrelated to either academic self-concept or valuing of academics.

\subsection{Implicit Associations Test (IAT) Results}

The average response times, in milliseconds, were recorded for the 7th, 8th, 9th, and 10th trials in the Implicit Associations Test. In the 7th and 9th trials, the word "Success" was paired with the word "Hispanic" and the word "Failure" was paired with the word "Caucasian". In the 8th and 10th trials, these word pairings were reversed. Participants were presented with either a word or a picture in the middle of the screen, and they had to categorize the words as representing success or failure and the picture as representing either a Hispanic or a Caucasian face (see Appendix A). Each trial contained 20 words or 
pictures for participants to categorize. The average reaction time across these 20 words or pictures was calculated for each of the four trials under consideration.

The average response times are presented in Figure 1. A repeated-measures ANOVA was conducted to compare the reaction times across the four trials. A statistically significant difference between the means was found $\left(F_{(3,76)}=8.79\right.$, partial $\left.\eta^{2}=0.10\right)$. The cubic effect was statistically significant $\left(F_{(1,72)}=19.48\right.$, partial $\left.\eta^{2}=0.20\right)$. An examination of the means revealed that the average reaction times were slower when Success was paired with Hispanic and faster when Success was paired with Caucasian. This pattern of implicit associations indicates that the sample of Hispanic high school students in our study implicitly associated success more with Caucasians than with Hispanics.

1500

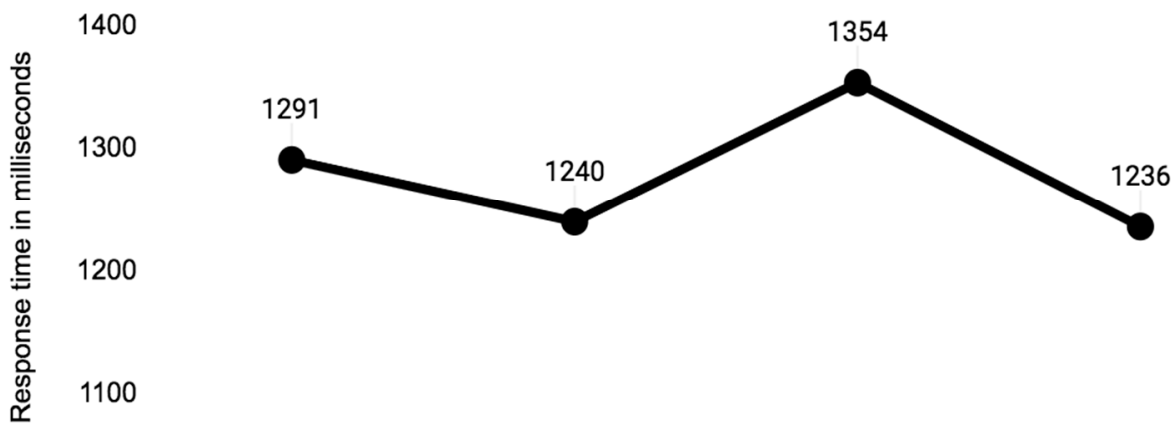

1000

\begin{tabular}{|c|}
\hline $\begin{array}{l}\text { Trial 7: Hispanic } \\
\text { Success }\end{array}$ \\
\hline
\end{tabular}

Figure 1. Average IAT response times for trials pairing Hispanic-Success/White-Failure and Hispanic-Failure/White-Success, in milliseconds.

Additional analyses of the IAT data were conducted to examine potential moderators of this pattern of implicit associations. We found no significant moderating effects of gender $\left(F_{(3,72)}=0.38, n s\right)$, whether the mother $\left(F_{(3,72)}=1.50, n s\right)$ or father $\left(F_{(3,72)}=0.64, n s\right)$ was an immigrant, or whether the student was an immigrant to the U.S $\left(F_{(3,72)}=0.29, n s\right)$. Similarly, the IAT pattern did not depend on whether participants identified more with their family's native culture, mainstream U.S. culture, both, or neither $\left(F_{(3,72)}=0.75, n s\right)$. We also found that the awareness of the negative stereotypes that others hold about the academic abilities of Hispanic students did not moderate the IAT pattern $\left(F_{(3,72)}=0.45, n s\right)$.

In addition to measuring reaction time, we also recorded how many words and pictures students correctly classified in each trial. There were combinations of 20 words and pictures presented in each trial. We found that an average of 16.39 out of 20 items were correctly categorized per trial. To determine whether errors in classification were associated with response times across the four trials, we added the total number of correct responses across the four trials for each participant as a covariate in the repeated-measures ANOVA examining changes in response time across the four trials. The addition of this covariate did not change the results, as the cubic effect was still statistically significant $\left(F_{(1,78)}=18.88\right.$, partial $\left.\eta^{2}=0.20\right)$.

\subsection{Association between Ethnic Identity and Implicit Associations}

We examined the association between implicit associations and the two dimensions of ethnic identity (Centrality and Regard) in two ways. First, we calculated Pearson correlations and found that neither the centrality nor the regard dimensions of ethnic identity were associated with response times or accuracy for the IAT categorizations in any of the four trials $\left(r^{\prime} s<0.23, n s\right)$. Next, we conducted two separate repeated-measures ANOVAs with 
response time across the four trials of the IAT as the within-subjects factor and centrality of ethnic identity as the covariate in the first analysis and the regard dimension of ethnic identity as the covariate in the second analysis. In each analysis, changes in response time across the four trials of the IAT became non-significant when controlling for a dimension of ethnic identity $\left(F_{(3,73)}=0.06\right.$ and $F_{(3,73)}=0.54, n s$, for ANOVAs controlling for the centrality and regard dimensions of ethnic identity, respectively). There is no significant interaction between changes in reaction time and either of the dimensions of ethnic identity when they are included as covariates, nor are the two dimensions of ethnic identity significantly associated with the average reaction time across the four trials.

\section{Discussion}

One of the major developmental tasks for adolescents and early adults is to forge a coherent identity that coordinates one's self-perceptions across multiple contexts. For Hispanic adolescents in the U.S., this task is complicated by the fact that Hispanics, as do all members of ethnic minority groups in the U.S., must develop their ethnic identities as members of their families' native Hispanic culture and as members of the dominant culture in the U.S [31,32]. The primary purpose of the present study was to examine, using a combination of explicit and implicit measures, the intersection of ethnic identity and academic motivation, particularly academic self-concept. We were particularly interested in the association between ethnic and academic self-perceptions among Hispanic students attending a majority-Hispanic high school, where the salience of ethnic identity, and subsequent stereotype threat activation, may be lower than it is for Hispanic students attending majority-white schools.

\subsection{The Associations among Ethnic Identity and Academic Motivation}

There is some evidence from previous research that having a strong centrality of ethnic identity is associated with worse motivational and performance outcomes for ethnic minority students when they are in contexts that may activate stereotype threat $[6,13,14]$. Prior research has found that Hispanic college students at a majority-white university had no correlation between their ethnic identity centrality and academic self-concept [15]. Steele [11] argued that one consequence of stereotype threat was a gradual disidentification with the domain in which the stereotype is present (e.g., math or physics for girls, school more generally for Black and Hispanic students). However, for stereotyped students who remain highly identified with the academic domain, it is possible that a different form of disidentification occurs. Specifically, academically successful minoritized students in stereotype threat situations may separate their ethnic identity from their academic selfconcept, producing a null correlation between those two aspects of identity. A similar phenomenon has been observed among women who are successful in mathematics [33].

In the present study, we hypothesized that the connection between ethnic identity and academic self-concept would be easier to maintain for Hispanic students attending a majority-Hispanic high school because stereotype threat is less likely to be activated when students are in the ethnic majority in the achievement context. This hypothesis was confirmed with a significant, positive correlation between centrality of ethnic identity and academic self-concept. Contrary to some earlier research, we did not find a correlation between centrality of ethnic identity and valuing of academics or feelings of belonging in school [3,4]. However, we did find a significant, positive correlation between the regard dimension of ethnic identity and feelings of belonging. Students who had more positive feelings about belonging to their ethnic group and about the accomplishments of that group felt a stronger sense of belonging in school. Given that over $80 \%$ of the students at the school were Hispanic, it makes sense that feeling good about membership in that group would be associated with stronger feelings of belonging in the school.

It is not clear why we found no association between centrality of ethnic identity and valuing of school. In some of the prior research that has found such an association, it appeared that families explicitly linked ethnic identity with academic achievement [26]. 
Other research that found positive correlations between centrality of ethnic identity, valuing of school, and feelings of belonging, did not examine these associations separately for different ethnic groups and did not report separate results for students who may have been in the ethnic majority in their schools [3]. We expected that students with stronger centrality of ethnic identity, and who felt positive about their membership in their ethnic group, would value school more and feel a greater sense of belonging there. Although we did find a positive association between belonging and the regard component of ethnic identity, the lack of association between centrality of ethnic identity, feelings of belonging, and valuing of academics may indicate that when students are in the ethnic majority, a strong ethnic identity is not a necessary protective factor for maintaining higher levels of academic valuing and belonging.

\subsection{Implicit Associations}

Although the results of our explicit measures revealed a positive association between ethnic identity and academic self-concept, the results of the implicit associations test suggest that our sample of Hispanic high school students tend to associate success with being white more strongly than with being Hispanic. It is important to keep in mind what the participant's task was when completing the IAT. They were not asked explicitly to indicate whether they thought success was more strongly associated with being Caucasian than with being Hispanic. Rather, they were simply engaged in a recognition task. As quickly as they could, they had to recognize whether a picture was of a Caucasian person or a Hispanic person or whether a word represented Success or Failure. We found that participants recognized and categorized these pictures and words more slowly when the word Success was in proximity to the word Hispanic than when it was near the word Caucasian. We believe that this slower reaction when Success and Hispanic were paired indicates that participants sub-consciously associated success more strongly with being Caucasian than with being Hispanic, even if they did not believe this consciously [34].

The finding that Hispanic students attending a majority-Hispanic high school would implicitly associate academic success more strongly with Caucasians than with Hispanics is somewhat counterintuitive. After all, the students in our sample had many examples within their school of academically successful Hispanic students, and virtually no examples of successful white students at the school. Yet despite having a strong sense of ethnic identity and positive feelings about their ethnic group, this sample of Hispanic students had the same pattern of IAT results (although somewhat weaker) as a sample of white students in our earlier work [15]. One explanation for this result may be that the IAT results simply reflect this sample's conscious awareness that society holds low academic expectations for Hispanic students. Even if the IAT results simply reflect more conscious awareness of the achievement gap, the nature of the IAT task suggests that this association of success and being Caucasian has taken hold even at the sub-conscious level and may have negative consequences for the motivation and aspirations of Hispanic students even if they do not consciously endorse this association.

Although it is likely that the IAT results reflect an awareness and some internalization of societal stereotypes about the relative abilities of Hispanic and white populations in the U.S., it does not appear that these sub-conscious associations have broken the link between ethnic identity and academic self-concept. Unlike previous research that has found no association between ethnic identity and academic self-concept (e.g., [3,15]), it appears that Hispanic students attending a majority-Hispanic school are better able to coordinate their ethnic and academic identities. We suspect that this may be due to the lack of stereotype threat activation among students attending schools in which they are the ethnic majority. Awareness of the negative stereotypes about their ethnic group may exist but will be less of a perceived threat of fulfilling the negative stereotype due to being in the ethnic majority. Additionally, the pernicious effects of disassociation between ethnic and academic identities do not seem to occur. 
Still, the finding of a stereotypical pattern in the IAT results is troubling. It suggests that these Hispanic students had internalized some of the dominant cultural beliefs, including the belief that academic success is more strongly associated with being Caucasian than with being Hispanic, even if they did not consciously believe these stereotypes. This troubling IAT pattern is consistent with research indicating that there are costs to Hispanics of acculturating too much into the dominant U.S. culture [35-37], including becoming aware of, and possibly internalizing, negative stereotypes about Hispanics in the U.S. We did not find evidence of variation in the IAT pattern depending on the generational status of the students, their parents, or with which culture (the dominant U.S. culture or the family's native culture) students more strongly identified with. However, we did find that the stereotypical IAT pattern became non-significant when controlling for either the centrality or the regard dimension of ethnic identity. It appears that the variability in reaction time on the IAT measure is associated with variability in the dimensions of ethnic identity. The lack of correlation between the dimensions of ethnic identity and reaction times, however, makes this reduction in significant changes across the four IAT trials when controlling for centrality and regard difficult to interpret.

\subsection{Limitations}

Several limitations in this study are worth noting. First, all of the Hispanic participants in this study were proficient English speakers, so in that regard they were all quite highly acculturated. Future research on this topic that includes more recent immigrants and those who are not proficient in English may offer a better test of the association between acculturation, ethnic identity, and academic motivation. In addition, this study was limited by a small sample size. Future research with larger numbers of participants in the various acculturation groups should shed light on whether and how acculturation is associated with implicit associations. In addition, this study employed the blanket ethnic label Hispanic to refer to a population that is, in fact, quite diverse. Although most of the Hispanics in this study had their family roots in Mexico, the Hispanic population in the U.S. differs by country of origin, financial and educational status both before and after immigration, and reasons for immigrating to the U.S., among other differences [38]. Research that more closely examines these differences within the Hispanic population is needed.

Finally, there are questions about the validity and reliability of the tests of implicit associations. Some research has demonstrated that IAT results can reliably demonstrate differences between groups in their implicit associations indicating average levels of preferences for things like different animals or sports teams [39]. However, there is no clear consensus about whether the IAT test measures implicit cognition. For example, some have argued that the IAT can clearly reveal hidden biases that individuals hold [40]. However, some attitudes fluctuate quite dramatically over time and across situations, making the significance of any single IAT measurement questionable [41]. Nonetheless, there is some evidence that IAT measures are valid measures of implicit social cognition, having demonstrated sound sociometric properties including reliability and predictive validity for some variables, including ethnic biases [42,43]. In the present study, our explicit, survey measure of students' awareness of how others perceive the academic abilities of Hispanic students was not significantly correlated with reaction times on the IAT. It is not clear whether this indicates a problem with the concurrent validity of the IAT or if it is an indication that the implicit associations students held were truly subconscious and therefore completely independent of any conscious beliefs they might hold. As others have noted, knowing about one's implicit biases does not necessarily reveal how one will behave as a result of those biases [44]. We found that Hispanic high school students implicitly associated success more with being white than with being Hispanic. The behavioral consequences of these implicit associations remain unknown. 


\subsection{Conclusions and Implications}

Despite the limitations of this study, we believe these results can provide a useful stepping-stone for further research in this area. One of the fundamental tasks of adolescence is to develop a coherent and consolidated sense of self. Ideally, the different aspects of the self would be complementary, such that positive self-perceptions in one important area (e.g., ethnic identity) are associated with positive self-perceptions in other important domains (e.g., academic self-concept). Previous research has sometimes found that among Hispanic students, particularly those attending majority white schools, the association between ethnic and academic self-perceptions has been severed. This can lead to disidentification with one or the other dimensions of the self, a potentially unhealthy outcome that can impair motivation and performance. When talented Hispanic students see no connection between their ethnic identity and their academic self-concept, some may feel that performing well in school comes at the cost of maintaining a strong connection to their ethnic group [5]. This perceived cost may lead some students to disidentify with school for the sake of maintaining a strong ethnic connection [23] and others to view their academic success as unrelated to their ethnic identity.

In the present study, we found that Hispanic students attending a majority-Hispanic high school did enjoy a positive association between the centrality dimension of ethnic identity and academic self-concept. We speculate that being in the majority reduced the salience of ethnic identity, thereby reducing stereotype threat. These results suggest that efforts to reduce stereotype threat for Hispanic students may benefit the coordination of the ethnic and academic dimensions of identity. However, the results from the IAT analysis indicate that even when in the majority in school, Hispanic students hold implicit associations that pair success more with being white than with being Hispanic. These stereotypical IAT patterns appear to be reduced when controlling for the centrality and regard dimensions of ethnic identity, indicating that variability in ethnic identity is associated with variability in IAT scores. Future research designed to better understand the association between implicit and explicit attitudes and how they might combine to influence academic motivation and behavior is needed. In addition, there is a need for interventions that can reduce the activation of stereotype threat and minimize the formation of implicit biases among students who identify with ethnic groups about which there are negative stereotypes about their academic abilities.

Author Contributions: T.U. conceptualized the study and collected the data. D.T. helped with the literature review, some of the data analysis, and some of the preparation of the manuscript. All authors have read and agreed to the published version of the manuscript.

Funding: This research received no external funding.

Institutional Review Board Statement: This study was approved by the institutional review board at Santa Clara University (protocol \#13-09-393) on 30 September 2016 and by the administrator of the high school where the study was conducted.

Informed Consent Statement: Informed consent was obtained from parents of all of the participants in this study. In addition, participants were informed of their rights as research participants and asked for their consent before they were allowed to complete any of the research activities.

Data Availability Statement: Data from this study will be made available from the corresponding author upon request.

Conflicts of Interest: The authors declare no conflict of interest.

\section{Appendix A}

Sample screenshots from the Implicit Associations Test (IAT). 


\begin{tabular}{|l|r|}
\hline $\begin{array}{l}\text { Hispanic or } \\
\text { Success }\end{array}$ & $\begin{array}{r}\text { Caucasian or } \\
\text { Failure }\end{array}$ \\
\hline
\end{tabular}

\section{Graduate}

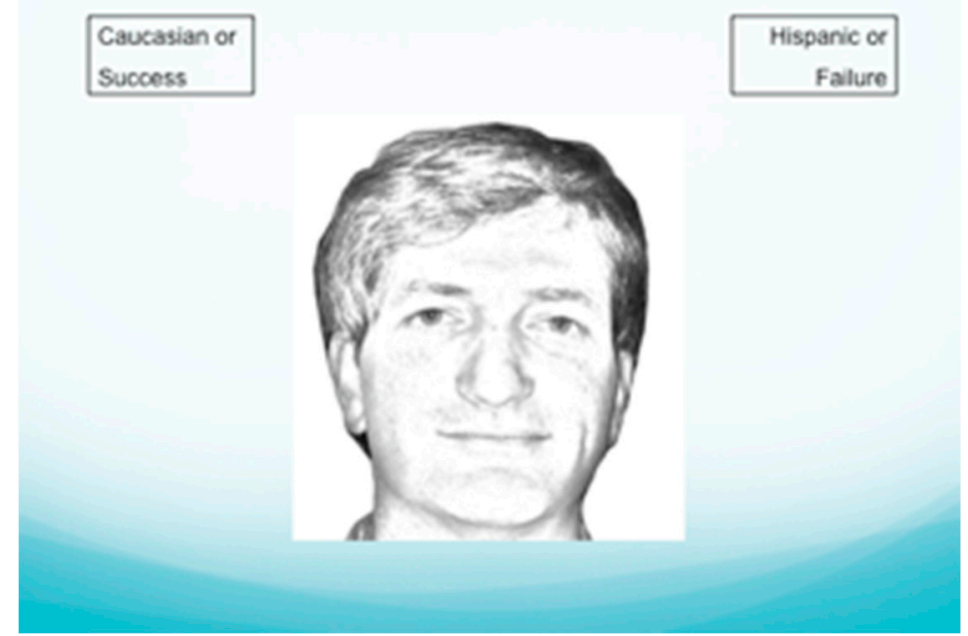

Figure A2. Sample screen from the IAT with a picture as the stimulus.

\section{References}

1. Sellers, R.M.; Smith, M.A.; Shelton, J.N.; Rowley, S.A.; Chavous, T.M. Multidimensional model of racial identity: A reconceptualization of African American racial identity. Pers. Soc. Psychol. Rev. 1998, 2, 18-39. [CrossRef] [PubMed]

2. Chavous, T.; Rivas-Drake, D.; Smalls, C.; Griffin, T.; Cogburn, C. Gender matters: The influence of school racial discrimination experiences and racial identity on academic adjustment among African American Adolescents. Dev. Psychol. 2008, 44, 637-654. [CrossRef]

3. Fuligni, A.J.; Witkow, M.; Garcia, C. Ethnic identity and the academic adjustment of adolescents from Mexican, Chinese, and European backgrounds. Dev. Psychol. 2005, 41, 799-811. [CrossRef] [PubMed]

4. Phinney, J.S.; Cantu, C.L.; Kurtz, D.A. Ethnic and American identity as predictors of self-esteem among African American, Latino, and White adolescents. J. Youth Adolesc. 1997, 26, 165-185. [CrossRef]

5. Ogbu, J.U. Understanding cultural diversity and learning. Educ. Res. 1992, 21, 5-14. [CrossRef]

6. Guyll, M.; Madon, S.; Prieto, L.; Scherr, K.C. The potential roles of self-fulfilling prophecies, stigma consciousness, and stereotype threat in linking Latino/a ethnicity and educational outcomes. J. Soc. Issues 2010, 66, 113-130. [CrossRef]

7. Gitlin, A.; Buendia, E.; Crosland, K.; Doumbia, F. The production of margin and center: Welcoming-unwelcoming of immigrant students. Am. Educ. Res. J. 2003, 40, 91-122. [CrossRef] 
8. Gonzalez-Berrera, A. The Way Hispanics Describe Themselves Vary across Immigrant Generations. Pew Research Center, 2020. Available online: https:/ /www.pewresearch.org/fact-tank/2020/09/24/the-ways-hispanics-describe-their-identity-vary-acrossimmigrant-generations/ (accessed on 3 May 2021).

9. Oakes, J. Keeping Track: How Schools Structure Inequality, 2nd ed.; Yale University Press: New Haven, CT, USA, 2005.

10. Appel, M.; Weber, S.; Kronberger, N. The influence of stereotype threat on immigrants: Review and meta-analysis. Front. Psychol. 2015, 6. [CrossRef]

11. Steele, C.M. A threat in the air: How stereotypes shape intellectual identity and performance. Am. Psychol. 1997, 52, 613-629. [CrossRef]

12. Woodcock, A.; Hernandez, P.R.; Estrada, M.; Schultz, P.W. The consequences of chronic stereotype threat: Domain disidentification and abandonment. J. Personal. Soc. Psychol. 2012, 103, 635-646. [CrossRef] [PubMed]

13. Weber, S.; Kronberger, N.; Appel, M. Immigrant students' educational trajectories. The influence of cultural identity and stereotype threat. Self. Identity 2018, 17, 211-235. [CrossRef]

14. Armenta, B.E. Stereotype boost and stereotype threat effects: The moderating role of ethnic identification. Cult. Divers. Ethnic Minor. Psychol. 2010, 16, 94-98. [CrossRef] [PubMed]

15. Urdan, T. Ethnic identity, academic motivation, and stereotype threat. In Proceedings of the Bi-Annual Meetings of the International Conference on Motivation, Helsinki, Finland, 12 June 2014.

16. Erba, J. Media representations of Latina/os and Hispanic students' stereotype threat behavior. Howard J. Commun. 2018, 29, 83-102. [CrossRef]

17. Sherman, D.K.; Hartson, K.A.; Binning, K.R.; Purdie-Vaughns, V.; Garcia, J.; Taborsky-Barba, S.; Tomassetti, S.; Nussbaum, A.D.; Cohen, G.L. Deflecting the trajectory and changing the narrative: How self-affirmation affects academic performance and motivation under identity threat. J. Personal. Soc. Psychol. 2013, 104, 591-618. [CrossRef]

18. Atkinson, J.W.; Feather, N.T. A Theory of Achievement Motivation; John Wiley and Sons: New York, NY, USA, 1966.

19. McClelland, D.C. How motives, skills, and values determine what people do. Am. Psychol. 1985, 40, 812-825. [CrossRef]

20. Schultheiss, O.C.; Rösch, A.G.; Rawolle, M.; Kullmann, J.; Kordik, A. Implicit motives: Current topics and future directions. In Advances in Motivation and Achievement, V. 16A: The Decade Ahead; Urdan, T., Karabenick, S., Eds.; Emerald Press: Castle Hill, NSW, Australia, 2010. [CrossRef]

21. Eagleman, D. Incognito: The Secret Lives of the Brain; Pantheon: New York, NY, USA, 2011.

22. Bassili, J.N. Response Latency and the Accessibility of Voting Intentions: What Contributes to Accessibility and How it Affects Vote Choice. Personal. Soc. Psychol. Bull. 1995, 21, 686-695. [CrossRef]

23. Steele, C.M.; Aronson, J. Stereotype threat and the intellectual test performance of African-Americans. J. Personal. Soc. Psychol. 1995, 69, 797-811. [CrossRef]

24. Fazio, R.H.; Dunton, B.C. Categorization by race: The impact of automatic and controlled components of racial prejudice. J. Exp. Soc. Psychol. 1997, 33, 451-470. [CrossRef]

25. Perdue, C.W.; Gurtman, M.B. Evidence for the automaticity of ageism. J. Exp. Soc. Psychol. 1990, 26, 199-216. [CrossRef]

26. Gibson, M.A. Accommodation Without Assimilation: Sikh Immigrants in an American High School; Cornell University Press: Ithica, NY, USA, 1988.

27. Alarcón, O.; Szalacha, L.A.; Erkut, S.; Fields, J.P.; Coll, C.G. The Color of My Skin: A Measure to Assess Children's Perceptions of Their Skin Color. Appl. Dev. Sci. 2000, 4, 208-221. [CrossRef]

28. Midgley, C.; Maehr, M.L.; Hruda, L.; Anderman, E.; Anderman, L.; Freeman, K.; Kumar, R.; Gheen, M.; Kaplan Middleton, M.; Nelson, J.; et al. Manual for the Patterns of Adaptive Learning Scales; University of Michigan: Ann Abor, MI, USA, 2000.

29. Berry, J.W. Acculturation as varieties of adaptation. In Acculturation: Theory, Models, and Some New Findings; Padilla, A., Ed.; Westview Press: Boulder, CO, USA, 1980; pp. 9-25.

30. Berry, J.W. Contexts of acculturation. In The Cambridge Handbook of Acculturation Psychology; Sam, D.L., Berry, J.W., Eds.; Cambridge University Press: Cambridge, UK, 2006; pp. 27-42.

31. Berry, J.W.; Phinney, J.S.; Sam, D.L.; Vedder, P. Immigrant youth: Acculturation, identity, and adaptation. Appl. Psychol. 2006, 55, 303-332. [CrossRef]

32. Portes, A.; Zhou, M. The New Second Generation: Segmented Assimilation and its Variants. Ann. Am. Acad. Polit. Soc. Sci. 1993, 530, 74-96. [CrossRef]

33. Pronin, E.; Steele, C.M.; Ross, L. Identity bifurcation in response to stereotype threat: Women and mathematics. J. Exp. Soc. Psychol. 2004, 40, 152-168. [CrossRef]

34. Fazio, R.H.; Olson, M.A. Implicit measures in social cognition research: Their meaning and use. Annu. Rev. Psychol. 2003, 54, 297-327. [CrossRef]

35. Bui, H.N.; Thongniramol, O. Immigration and self-reported delinquency: The interplay of immigration generations, gender, race, and ethnicity. J. Crime Justice 2005, 28, 71-99. [CrossRef]

36. Gonzales, N.A.; Fabrett, F.C.; Knight, G.P. Acculturation, enculturation, and the psychosocial adaptation of Latino youth. In Handbook of U.S. Latino Psychology: Developmental and Community-Based Perspectives; Villarruel, F.A., Carlo, G., Grau, J.M., Azmitia, M., Cabrera, N.J., Chahin, T.J., Eds.; Sage Publications Inc.: Los Angeles, CA, USA, 2009; pp. 115-134.

37. Padilla, A.M. Bicultural Social Development. Hisp. J. Behav. Sci. 2006, 28, 467-497. [CrossRef] 
38. Fernandez-Kelly, P. The back pocket map: Social class and cultural capital as transferable assets in the advancement of secondgeneration immigrants. Ann. Am. Acad. Polit. Soc. Sci. 2008, 620, 116-137. [CrossRef]

39. Schimmack, U. The Implicit Association Test: A Method in Search of a Construct. Perspect. Psychol. Sci. 2019. [CrossRef]

40. Banaji, M.R.; Greenwald, A.G. Blindspot: Hidden Biases of Good People; Delacorte Press: New York, NY, USA, 2013.

41. Payne, B.K.; Vuletich, H.A.; Lundberg, K.B. The bias of crowds: How implicit bias bridges personal and systemic prejudice. Psychol. Inq. 2017, 28, 233-248. [CrossRef]

42. Dentale, F.; Vecchione, M.; Gebauer, J.E.; Barbaranelli, C. Measuring automatic value orientations: The Achievement-Benevolence Implicit Association Test. Br. J. Soc. Psychol. 2018, 57, 210-229. [CrossRef]

43. Karpinski, A.; Steinman, R.B. The Single Category Implicit Association Test as a measure of implicit social cognition. J. Personal. Soc. Psychol. 2006, 91, 16-32. [CrossRef] [PubMed]

44. Rae, J.R.; Olson, K.R. Test-retest reliability and predictive validity of the Implicit Association Test in children. Dev. Psychol. 2018, 54, 308-330. [CrossRef] [PubMed] 